\title{
EM MEMÓRIA DE TEMPOS MELHORES: OS ANTROPÓLOGOS E A LUTA PELO DIREITO
}

\author{
Rita Laura Segato \\ Universidade de Brasília - Brasil
}

São várias as perguntas e francas objeções que surgem à medida que passo as folhas do texto de Marcos Chor Maio e Ricardo Ventura nesta minha segunda leitura do mesmo. Por tratar-se de questões de ordens muito diferentes, procedo a numerá-las numa hierarquia que vá das mais pontuais - relativas a problemas na argumentação, metodológicos e factuais -, até as questões mais filosóficas - sobre o conteúdo mesmo das afirmações dos autores.

Agradeço aos editores deste número de Horizontes Antropológicos, Carlos Albert Steil e Sérgio Alves Teixeira, por haverem-me convidado e finalmente convencido a participar do debate, dando-me com isso a oportunidade de tornar pública a minha crítica e compartilhar com os leitores a série de incorreções que identifico no texto sob escrutínio.

A primeira, que também será certamente a última a ficar na esteira da leitura, é sobre o pretendido caráter científico e disciplinar do artigo onde avaliam o método de identificação racial utilizado pela Universidade de Brasília. Pergunto-me: o exame dos fatos e das citações por eles cuidadosamente escolhidos num recorte contextual pelo menos discutível tenta responder uma pergunta autêntica, da qual não se conhecia resposta antes do exercício disciplinar? Ou trata-se de uma estratégia para instilar uma opinião maquiada de resultado laboratorial? É inevitável para mim, uma vez interpelada e atraída pelos editores da revista a mergulhar nessa segunda leitura, mencionar a dúvida que paira sobre o sentido e a finalidade da diligência dos autores.

Parece-me aceitável que eles tenham opinião, e que a opinião deles seja diferente da minha, mas não que apresentem sua opinião sob as vestes de neutralidade de um argumento científico. Concordar ou não concordar 
com uma política de cotas para estudantes negros para a universidade brasileira são duas posições valorativas e ideológicas frente à sociedade e à universidade, são diferenças de ponto de vista sobre o que é melhor para o país. Não são resultados de um exercício disciplinar. Se o exercício disciplinar deve, necessariamente, acompanhar a opinião para demonstrar que ela possui fundamento, isso, contudo, não autoriza os autores a omitir a explicitação da sua posição sobre o assunto e substituí-la pelo que é apresentado como exercício puramente disciplinar e neutro, a risco de que o resultado suscite a dúvida que estou justamente descrevendo: que se trata de um contrabando ideológico embrulhado no linguajar de aparência sistemática e laboratorial. A opinião de Maio e Santos chega a nós num invólucro, dissimulada por trás de um recortado conjunto de citações de textos autorais ou institucionais, assim como de depoimentos de pessoas, que acaba funcionando como uma verdadeira cortina de fumaça para esconder o que não teria por que estar oculto: o que eles pensam sobre abrir as portas da universidade a um tipo de pessoas que não a freqüentam atualmente e cuja marca de exclusão radica na cor da pele em associação com outros dados fenotípicos. Se, por um lado, a opinião deve amparar-se em fatos, o recorte dos fatos não pode tentar escamotear a opinião que lhe dita o rumo.

Uma variedade de táticas de indefinição e ocultamento como a apontada revela-se recorrente na construção do texto aqui analisado.

Por exemplo, ao traçar seu recorte do processo que levou à instalação de um sistema de cotas na Universidade de Brasília, os autores, prisioneiros de um preconceito comum a muitos dos que abraçaram recentemente o estudo das políticas públicas numa perspectiva antropológica, as abordam já em andamento, como se ditas políticas pudessem surgir de um vácuo sociológico e histórico ou resultassem da espontânea magnanimidade daqueles que ocupam os cargos de governo - nesse caso, do governo da instituição universitária. Um pouco de história bastaria para constatar que doações desse tipo, que acabam inaugurando um novo período na história de um país, são sempre conseqüência de pressões emanadas de atores sociais ao exterior do grupo doador. Não estamos no campo da caridade, estamos no campo da política. 
O processo que culmina com a instalação das cotas na UnB não foi diferente. Ele é o resultado da luta iniciada pelo estudante negro de doutorado do Departamento de Antropologia da Universidade de Brasília, Ariovaldo Lima, que fora penalizado injustamente por um dos seus professores e vitimizado pela indiferença anacrônica e pouco informada da maioria dos docentes desse departamento. Estes, desconhecendo convenções, declarações, recomendações e uma variedade de outros instrumentos da legislação internacional relativa à importância da promoção da igualdade racial, da discriminação positiva e da inclusão racial nas profissões e na educação já existentes à época, permaneceram ignorantes da importância da sua presença diferenciada no meio acadêmico em razão da sua cor e de um conjunto de outras características que, como conseqüência da história da escravidão no Brasil, emolduram seu fenótipo. A luta solitária de Ari - que não entregou seus direitos, não acatou a suspeita por momentos generalizada sobre sua capacidade de obter o título máximo numa instituição de excelência, não se amedrontou com as ameaças e obstáculos que lhe foram interpostos, e acabou vencendo na sua luta pessoal e coletiva até se doutorar com louvor no mesmo claustro acadêmico que o tinha maltratado -, somada à dos poucos que com ele se solidarizaram, instala, na Universidade de Brasília, tão cedo como 1998, a luta por conceber, projetar e conseguir implantar o primeiro sistema de cotas para estudantes negros que surge da vida interna de uma universidade, da intimidade mesma de seu cotidiano institucional e no exercício pleno da sua autonomia. Mais tarde, as autoridades e todos aqueles por elas designados fizeram eco a esse clamor que vinha de baixo e que já tinha alcançado os corredores ministeriais e as páginas da imprensa na cidade e no Brasil. Era necessário mostrar que a Universidade de Brasília era uma universidade com capacidade de autocorreção e dignidade institucional.

O primeiro momento dessa história - de conseqüências em escala nacional na época imprevisíveis - não é assim tão remoto ou irrelevante como para ter sido omitido por Marcos Chor Maio e Ricardo Ventura de seu prolixo relatório: foi a elevação do Caso Ari ao cenário político dentro da universidade, por parte do professor José Jorge de Carvalho, em colaboração comigo, quando apresentamos o primeiro rascunho da nossa Proposta de Cotas para Estudantes Negros (em seguida ampliada para incluir candidatos indígenas), inicialmente em evento organizado pelo Núcleo de Estudos Afro-Brasileiros (Neab) da UnB, em 17 de novembro de1999, e 
logo depois no Auditório da Reitoria da Universidade de Brasília, em 6 de dezembro de 1999. O segundo momento foi a sinalização positiva dada pela comunidade universitária quando o Conselho de Ensino, Pesquisa e Extensão, na sessão de 19 de maio de 2000, reconheceu oficialmente que a nota que Ari tinha recebido era injusta, mudou a avaliação do professor e restituiu ao estudante os créditos perdidos sem necessidade de cursar novamente a disciplina obrigatória. As autoridades competentes, representadas aqui pelo vice-reitor da universidade, professor Timothy Mulholand, e os representantes de departamentos e institutos, com atuação destacada do professor Volnei Garrafa, do Departamento de Bioética, se mostravam, fora de qualquer dúvida, sensíveis ao problema do negro na Universidade de Brasília. Foi essa luta, de baixo para cima, detonada por um caso ocorrido em 1998 e formalizada com a primeira apresentação oficial da nossa proposta em 1999, que levou as cotas ao debate interno da universidade e ao debate nacional, vindo a convergir com o processo da Conferência Mundial Contra o Racismo, de Durban, até alcançar sua atual dimensão de política pública num projeto nacional de inclusão racial nas instituições acadêmicas.

Gostaria também de esclarecer, para o benefício dos leitores, que, finalmente, o texto Proposta de Cotas para Estudantes Negros e Indígenas na Universidade de Brasília, elaborado por mim e por José Jorge de Carvalho, foi votado e aprovado na íntegra e sem modificações pelo Conselho de Ensino, Pesquisa e Extensão da UnB em 6 de junho de 2003 e circulou - e ainda circula - no site da Universidade de Brasília e muitas outras páginas da Web, como o n. 314 da Série Antropologia (Carvalho; Segato, 2002). Mais uma vez, resulta inconcebível sua ausência nas quatro páginas da bibliografia apresentada por Maio e Santos. Não somente ele não previa a prova fotográfica da negritude, como os autores reconhecem, mas incluía três órgãos suplementares para o acompanhamento do processo: uma ouvidoria universitária para estudantes e outros membros da comunidade acadêmica em situação vulnerável, uma comissão de acompanhamento psicopedagógico e uma comissão de monitoramento da medida, o que mais tarde veio a coincidir com uma das recomendações da Conferência de Durban (voltarei a referir-me a esta última). Nenhuma delas foi considerada no processo de implementação. No seu defeito, uma Comissão Especial foi constituída para fazer a triagem dos que qualificam 
para o benefício, da qual nem o professor José Jorge de Carvalho nem eu fazemos parte.

O mesmo espírito discricionário na seleção e apresentação dos fatos até aqui apontados afeta um dos argumentos centrais do artigo em questão. Trata-se do suposto engano da Universidade de Brasília ao tentar definir quem é negro e, portanto, qualifica ao ingresso por cotas, e da sua infração ao princípio de auto-atribuição ou autodeclaração. Mais uma vez, para tratar esse ponto, Maio e Santos se poupam do risco de exibir sua voz autoral num texto que, com efeito, é a todas vistas interessado, e optam por escudar-se na palavra da Associação Brasileira de Antropologia sobre o tema. Ao fazêlo, induzem também o leitor a desistir de toda e qualquer dúvida a respeito dos mecanismos de ordem corporativa que investem essa palavra de uma autorização disciplinar. De novo, os autores tentam passar gato por lebre, fazendo que os incautos acreditem que o papel da ABA é científico, no sentido de que a sua palavra representa a postura teórico-metodológica e os resultados de todos os seus membros. Ora! Seria esta a pior associação científica do mundo se ela contasse com tal unidade dos procedimentos, abordagens e posturas de toda a comunidade disciplinar que representa! E, mais grave ainda, não resulta claro para o leitor se deve ou não supor que a ABA é citada porque os autores são sócios dela, por presumi-la cientificamente autorizada, ou por eles concordarem com o parecer emitido pela associação e tentarem, então, mais uma vez, introduzir sua própria voz ao abrigo de outra.

De qualquer forma, o citado texto da Comissão de Relações Étnicas e Raciais da ABA (Crer-ABA) diz ter decidido adiar para alguma outra ocasião um pronunciamento a respeito da política de cotas e permite, assim, que seus membros evitem assumir uma posição pública a respeito, mas faz um gesto por demais confortável e não muito diferente ao dos autores comentados: se pronuncia obliquamente, indiretamente, atacando o aspecto mais frágil do procedimento posto em prática pela UnB: fotografar os candidatos e constituir uma comissão de triagem, alegando que tais procedimentos "constrangem o direito individual, notadamente o da livre auto-identificação”. A isto, acrescenta uma enigmática alusão ao "arcabouço conceitual das ciências sociais, e, em particular, da antropologia social e 
antropologia biológica” que a UnB, com seu procedimento, estaria desconhecendo, e de passo insinua, com isso, que a associação conta com a unanimidade conceitual monolítica de seus membros.

É possível que o leitor pouco iniciado nos processos de fundação da antropologia brasileira tal como hoje a conhecemos fique perplexo ao perceber que tanto Maio e Santos como os antropólogos que assinam o documento da ABA encontrem a idéia de raça tão misteriosa (mais misteriosa que a definição de tipos ou classes em qualquer sistema conhecido de classificação, com sua habitual margem de erro e ambigüidade). É realmente difícil de explicar que uma ciência que transita assiduamente pela noção da representação social e de símbolo se mostre tão incapaz de entender que, numa história particular como é a história da conquista e a colonização da África e da conseqüente escravização de parte de sua gente, o signo da pele negra é lido como diacrítico de pertencimento ao povo subalternizado por esses processos, e que isso nada tem a ver com quantidade ou tipo de genes. A proximidade daqueles marcados por esse signo desvaloriza os cenários da vida social, a não ser que se encontrem num claro papel de subserviência, e faz tremer de pânico social a todos aqueles que pouco atrás exibiam sua marca e conseguiram, graças à miscigenação programada no seio das famílias, deixá-la para trás. Então, ser negro, ser racialmente marcado com a marca da África no Brasil não é ser afrodescendente, já que no Brasil existem milhões de afro-descendentes hoje percebidos como brancos. Mas é ser alguém que, até às vezes em conseqüência da loteria genética que entra em ação sempre que se gera vida, exibe a marca do passado mais temido, de uma inferioridade historicamente herdada e cuidadosamente ocultada no fundo do baú das melhores famílias. Então, o racismo à brasileira fala disto: de que determinados signos fenotípicos tomam seu significado de uma história de guerra, escravização e, já neste século, sistemática exclusão, e que o que importa desses signos é somente seu impacto visual num código de leitura intensamente influenciado por essa história. Impressiona também que certos antropólogos que dedicaram boa parte de sua vida profissional a gerenciar programas de apoio para os escassos estudantes negros que freqüentam a universidade hoje se neguem a aceitar o critério de raça, no sentido literal de cor e fenótipo, como suporte para uma política de cotas nas universidades. O leitor pode se perguntar, então: como esses professores 
definem os beneficiários dos programas que eles mesmos dirigem? Não é, por acaso, segundo um critério também baseado na cor?

Chego, finalmente, ao ponto da autodeclaração, cerne do argumento dos autores comentados na sua velada tentativa de convencer-nos de que um sistema de cotas para negros na universidade não pode ser viável - se somente a autodeclaração é legítima e o fenótipo se dilui como parâmetro para a política inclusiva, então estamos expostos a todo tipo de argumento por parte dos interessados e à ampliação indefinida dos critérios que qualificam para participar. Com isso, sem clientela claramente definível, toda a política cai por terra. Há, aqui, muito a dizer para mostrar que as perspectivas não são tão sombrias assim como os autores querem supor.

Em primeiro lugar, chamar a atenção do leitor de que as lideranças negras não se manifestaram, até hoje, tão ofendidas quanto os membros da comunidade antropológica a respeito da necessidade de cercar critérios objetivos para definir quem pode e quem não pode ser beneficiário da medida. Cabe-se perguntar o porquê da imensa sensibilidade antropológica perante o suposto cerceamento da liberdade de se autodeclarar por parte dos candidatos negros, quando nos próprios grupos interessados na medida isso se apresenta como um problema menor e insuficiente para fazer uma crítica importante ao processo como um todo. Gostaria de saber onde se origina a pressa súbita desses antropólogos de oferecer aos negros brasileiros sua proteção perante os males de um sistema de cotas que lhes abrira as portas da educação superior.

Nem José Jorge nem eu incluímos o critério da fotografia e da comissão de triagem no projeto submetido ao conselho, mas uma das razões pelas quais não o incluímos é porque previmos que a função de vigilância estaria a cargo do que chamamos, no nosso texto, de "Comissão de Monitoramento". Ou seja, o controle do universo dos candidatos iria se processar depois do ingresso e não antes, e o método consistiria na sanção social e na reprovação da ação fraudulenta pela comunidade acadêmica. Essa comissão teria a seu cargo avaliar, a partir da primeira experiência, os níveis de fraude, e propor critérios de autocorreção da medida, não descartando eventualmente algum processo prévio de seleção dos que qualificam. Isso porque, conhecendo as práticas e orientações dominantes da 
disciplina antropológica no Brasil de uma forma que a reitoria da UnB não poderia conhecer, queríamos evitar justamente o que ocorreu: oferecer alvos às vozes que com certeza iriam se levantar tentando invalidar o processo posto em marcha.

De fato, basta uma linha para esclarecer o óbvio: que o critério de exclusiva autodeclaração racial adotado pelo IBGE responde a uma finalidade de medição demográfica e dele não depende nenhum benefício direto para os autodeclarantes; e que nenhum instrumento internacional que recomenda a inclusão racial estabelece como mandatório o critério de autoatribuição, exceto a Convenção 169 da OIT, ratificada pelo Brasil em 2002, que não legisla para indivíduos, mas para coletivos - os povos indígenas originários.

A presente convenção aplica-se:

a) aos povos tribais em países independentes, cujas condições sociais, culturais e econômicas os distingam de outros setores da coletividade nacional, e que estejam regidos, total ou parcialmente, por seus próprios costumes ou tradições ou por legislação especial;

b) aos povos em países independentes, considerados indígenas pelo fato de descenderem de populações que habitavam o país ou uma região geográfica pertencente ao país na época da conquista ou da colonização ou do estabelecimento das atuais fronteiras estatais e que, seja qual for sua situação jurídica, conservam todas as suas próprias instituições sociais, econômicas, culturais e políticas, ou parte delas.

Para eles, sim, a convenção garante que "a consciência de sua identidade indígena ou tribal deverá ser considerada como critério fundamental para determinar os grupos aos que se aplicam as disposições da presente Convenção”.

Certamente já houve melhores tempos para a antropologia, como aqueles da grande amizade e luta conjunta do eminente ativista e intelectual negro W.E.B. Du Bois com o antropólogo alemão e judeu emigrado Franz Boas. E houve também épocas mais interessantes para a reflexão sobre identidade étnica e racial, como a da chegada de Franz Fanon a Paris e a do encontro de Hans Maier/Jean Améry com o nazismo. 
E é com as lições deste último autor, a quem considero o Fanon judaico e cuja leitura recomendo, que encerro esta resposta a Marcos Chor Maio e Ricardo Ventura.

É sob a forma de condena que Jean Améry se encontra com sua identidade judia. Antes das leis de Nuremberg não há, nele, nenhum traço de cultura que o distinga do jovem tirolês mais comum; sua mãe, católica, reza e executa os rituais natalinos de cada ano. Seu sangue judeu vem do pai. Améry, que ao terminar a guerra adota este outro nome, não marcado pela germanicidade traiçoeira, conta: "eu adquiri realidade em Auschwitz. E somente uma total cegueira social e histórica poderia negar que esta identidade é, contudo, real.” (Améry, 2001, p. 190, tradução minha). Ele pertencia ao grupo que Sartre "sem formular nenhum julgamento de valor, chama de 'judeu inautêntico', isto é, aquele que sucumbiu ao mito do 'homem universal”. Da mesma forma, o negro brasileiro de nossos dias estaria certo se dissesse de si: "Eu adquiri realidade na escravidão, e esse sentimento de realidade se reafirmou com a chegada dos imigrantes europeus e a exclusão dela resultante". Um destino de sofrimento e subalternidade comum e seu reconhecimento, a posteriori da ação destrutiva iniciada e imposta pelo outro (alemão ou português) é, em última instância, quando não há a positividade da diferença dos costumes compartilhados nem uma clara herança cultural diacrítica, o que constitui uma identidade. Nesse sentido, em alguns casos, o pertencimento a um coletivo racial é conseqüência do olhar externo sobre ele, é resultado da exclusão, da discriminação, do maltrato.

O fenótipo judeu que talvez, eu não sei, me seja próprio, concerne, como problema, aos outros e somente se torna assunto meu na relação objetiva que eles pretendem me impor. (Améry, 2001, p. 187, tradução minha).

Há, segundo Améry, o que considero ser a única grande vantagem nessa identidade negativa:

que o anti-semitismo e a questão judaica como constelação de fenômenos históricos, sociológicos e ideológicos nem me interessavam nem me interessam. São exclusivamente assunto dos anti-semitas, sua infâmia ou sua doença. São os anti-semitas os que devem superá-la, não eu. (Améry, 2001, p. 181, tradução minha).

Da mesma forma, eu disse que 
a enfermidade do racismo e de todas as formas de discriminação residem naqueles que as exercem, e não em suas vítimas (quando estas são capazes de se reconhecerem como tais), sendo, portanto, a humanidade daqueles, com todos os seus reais privilégios associados, a que se deteriora e não, como comumente se pensa, a destes. [...] (As) fronteiras da confrontação e do estranhamento (são) perniciosamente inscritas pelos mecanismos de dominação. (Segato, 1995, p. 598).

A vítima de discriminação racial sempre será, em alguma medida, ingênua e desprevenida frente a quem a discrimina, porque ela é somente a depositária de um processo que não se origina nela e do qual ela conhece menos que o discriminador. Nesta perspectiva, o critério auto-adscritivo fica em parte comprometido, relativizado, a não ser como possibilidade de se reconhecer nesse lugar resultante de séculos de opressão imposta de fora. A identificação é pura negatividade que se reverte em positividade para reclamar devoluções, direitos, reparação.

\section{Referências}

AMÉRY, Jean. Más allá de la culpa y la expiación: tentativas de superación de una víctima de la violencia. Valencia: Pre-Textos, 2001.

CARVALHO, José Jorge de; SEGATO, Rita Laura. Uma proposta de cotas para estudantes negros e na Universidade de Brasília. Brasília: Universidade de Brasília, Departamento de Antropologia, 2002. (Série Antropologia, n. 314). Disponível em: <http://www.unb.br/ics/dan/ Serie314empdf.pdf $>$. Acesso em: 21 fev. 2005.

SEGATO, Rita Laura: Cidadania: por que não? Dados: Revista de Ciências Sociais, Rio de Janeiro, v. 38, n. 3, p. 581-602, 1995. 